\title{
Constipation and LUTS - How do They Affect Each Other?
}

\author{
Marcio A. Averbeck, Helmut Madersbacher
}

Department of Urology (MAA), Mae de Deus Center Hospital, Porto Alegre, Brazil and Department of Neurology (HM), Medical University Innsbruck, Innsbruck, Austria

\begin{abstract}
Context: Urinary bladder and rectum share a common embryological origin. Their autonomic and somatic innervations have close similarities. Moreover, the close proximity of these two organ systems could suggest that dysfunction in one may influence, also mechanically, the function of the other. Therefore, it is not surprising that defecation problems and lower urinary tract symptoms (LUTS) occur together, as reported in the literature.

Objective: To study the relationship between constipation and LUTS focusing on what is evidence-based.

Evidence acquisition: We searched the Medical Literature Analysis and Retrieval System Online (MEDLINE) database in February 2010 to retrieve English language studies (from 1997 to 2009) and the 2005, 2006 and 2007 abstract volumes of the European Association of Urology (EAU), American Urological Association (AUA) and International Continence Society (ICS).

Evidence synthesis: We present the findings according to the studied population in four groups: (a) children, (b) middleaged women, (c) elderly and (d) neuropathic patients. Most published studies that correlated rectal and bladder dysfunction were carried out in children or in young women. On the other hand, there are few studies regarding the association between constipation and LUTS in the elderly and in neuropathic patients.

Conclusions: Several studies in children documented that constipation is linked to urinary tract problems, including infections, enuresis, vesicoureteral reflux and upper renal tract dilatation. The underlying pathophysiology of these findings has not yet been clearly defined. Studies in middle-aged women also support a high prevalence of constipation among patients suffering from urinary tract dysfunction. Furthermore, an association between constipation and urinary incontinence, as well as between constipation and pelvic organ prolapse, has been suggested. The only prospective study in constipated elderly with concomitant LUTS demonstrates that the medical relief of constipation also significantly improves LUTS. Finally, the available data on neuropathic patients suggest that stool impaction in the rectum may mechanically impede bladder emptying. However, most of the studies only include a small number of patients, are not prospective and are uncontrolled. Therefore, there is a need for large-scale, controlled studies to further improve evidence and to provide a valid recommendation for all groups, especially for the elderly and neuropathic patients.
\end{abstract}

Key words: constipation; defecation; urinary tract; urinary tract diseases; urinary incontinence Int Braz J Urol. 2011; 37: 16-28

\section{INTRODUCTION}

The urinary bladder and the rectum have a common embryological origin in the cloaca. The motor nerve supply of each is provided by the para- sympathetic outflow arising from S2-S4. The same is true for the external (striated) anal and for the external (striated) urethral sphincter; both are innervated by the pudendal nerve, arising from the Onuf's nucleous in S2-S4. In healthy individuals bladder and rectum 
function are "in harmony" (1). However, constipation and lower urinary tract symptoms (LUTS) can occur concomitantly in children, women, the elderly, as well as in neuropathic patients.

Autonomic reflex interaction between the urinary bladder and the distal part of the gastrointestinal tract has been investigated in animal models and humans (2). It has been demonstrated that anal stimulation abolishes a prevailing detrusor contraction. On the other hand, distension of the urinary bladder in man produces an increase in internal anal sphincter pressure. This response is abolished by blockade of the thoracolumbar sympathetic outflow by epidural anaesthesia, indicating a spinal reflex arc (2).

The coincidence of defecation problems and LUTS reported in the literature may have several different aetiologies: (a) it may be that rectum and bladder are affected by the same neuropathology; (b) that dysfunction in one system may impede the neighbouring organs and structures mechanically, e.g. stool impaction from severe constipation may impede voiding; or (c) severe straining due to constipation may induce changes in the pelvic floor musculature, resulting in pelvic organ prolapse (POP) and urinary incontinence.

Most studies that correlated rectal and bladder dysfunction were carried out in children or in middleaged women, but there is only one prospective cohort study, to our knowledge, regarding constipation and LUTS in the elderly (1). One of the difficulties to conduct clinical studies, including bowel dysfunction is the subjective aspect associated with the definition of constipation (3). Some studies used self-applied questionnaires where the patients could define themselves as constipated or not. Only recently, has chronic functional constipation been clearly defined (4).

The aim of this review was to study the relationship between constipation and LUTS, focusing on what is evidence-based and what can be recommended so far from the diagnostic and therapeutic point of view.

\section{EVIDENCE ACQUISITION - SEARCH STRATEGY}

A literature search was performed in the Medical Literature Analysis and Retrieval System
Online (MEDLINE) database in February 2010 to retrieve English language studies (from 1997 to 2009) on the association between constipation and LUTS.

For retrieving the references in MEDLINE we used the following medical subject heading terms: "constipation" (major subject descriptor) and "defecation", "urinary tract", "urinary tract diseases", "urinary tract infections", "urinary incontinence" or "urinary retention" (subject descriptors). Furthermore, we searched the abstract volumes of the annual meetings of 2007, 2008 and 2009 of the European Association of Urology the American Urological Association and the International Continence Society meetings.

\section{DEFINITION OF CONSTIPATION}

Constipation is an end-point defined by a constellation of symptoms, including infrequent passage of stool, faeces that are either large, hard or in small pieces, abdominal pain, palpable stool in the abdomen, stool in the rectal vault or faecal soiling. Functional constipation (FC) is considered a symptom-based disorder that is characterized by both decreased frequency and hard consistency of stools, as well as symptoms relating to difficult evacuation (5). Table-1 presents the Rome III criteria for chronic functional constipation in adults and in children (4). Other terms and definitions have been used by some authors. Obstructive defecation was defined as difficulty in passing stool, hard stool, straining for more than 15 min., or incomplete evacuation, occurring at least weekly (6). Anal incontinence was defined as involuntary leakage of solid or liquid faeces or gas (7). Finally, dysfunctional elimination syndrome (DES) has been defined as any pattern of voiding or stooling that varies from the developmental norm (8).

\section{EVIDENCE SYNTHESIS ACCORDING TO THE STUDIED POPULATION}

The studies on Constipation and LUTS will be presented and discussed, as well as the levels of evidence (LoE) and grades of recommendation (GR). The publications were organized according to the studied population in four groups: Children, 
Table 1 - Rome III criteria for defining chronic functional constipation in adults and children (4).

\section{Adults}

Diagnostic criteria*

1. Must include two or more of the following:

a. Straining during at least $25 \%$ of defecations

b. Lumpy or hard stools in at least $25 \%$ of defecations

c. Sensation of incomplete evacuation for at least $25 \%$ of defecations

d. Sensation of anorectal obstruction/blockage for at least $25 \%$ of defecations

e. Manual manoeuvres to facilitate at least $25 \%$ of defecations (e.g., digital evacuation, support of the pelvic floor)

f. Fewer than three defecations per week

2. Loose stools are rarely present without the use of laxatives

3. Insufficient criteria for irritable bowel syndrome

* Criteria fulfilled for the last 3 months with symptom onset at least 6 months prior to diagnosis

\section{Children}

Diagnostic criteria must include one month of at least two of the following in infants up to 4 years of age

1. Two or fewer defecations per week

2. At least one episode/week of incontinence after the acquisition of toileting skills

3. History of excessive stool retention

4. History of painful or hard bowel movements

5. Presence of a large fecal mass in the rectum

6. History of large diameter stools which may obstruct the toilet

Accompanying symptoms may include irritability, decreased appetite, and/or early satiety. The accompanying symptoms disappear immediately following passage of a large stool.

Middle-Aged Women, Elderly, Neuropathic Patients. We were able to retrieve altogether 8 case-reports, 5 review studies, 3 case-control studies, 3 case-series, 6 cross-sectional studies, 5 cohort studies and 1 noncontrolled clinical study. Table-2 lists the review articles on constipation and LUTS published so far. Table-3 and Table-4 lists the published studies on children and middle-aged women, respectively, and Table-5 shows the studies, only case-reports, in neuropathic patients.

\section{CONSTIPATION AND LUTS IN CHILDREN}

Constipation is responsible for $3 \%$ of visits to a paediatrician and $25 \%$ of consultations with a gastroenterologist. Children diagnosed with constipation frequently have a poor appetite and have been shown to have a lower calorie and fibre intake, lower body mass index and more frequent anorexia than non-constipated children (9). Some children voluntarily suppress the urge to defecate and they refuse toileting, although a strong need to defecate is present. Withholding behaviour over time can cause DES (8). This behaviour may be due to an impairment of learning subsequent to distress, trauma, disruption of routine, inattention or cognition difficulties and is often associated with the memory or expectation of pain at defecation. Also the presence of an anal fissure or an anal streptococcal infection may induce this behaviour (9). Environmental factors regarding toilets, lack of privacy, risk of bullying, limited access, lack of essential products for good hygiene and dirty bathrooms can all contribute in encouraging a child to withhold urine and stool while at school.

There are 12 studies addressing the relationship between constipation and LUTS on children 
Table 2 - Review studies on constipation and LUTS in the literature.
Refs.
Title

Halachmi et al. (2008) The impact of constipation on the urinary tract system

Clayden et al. (2007) Constipation and incontinence in childhood: two sides of the same coin?

Kistner M. (2009) Dysfunctional elimination behaviours and associated complications in school-age children

Giramonti et al. (2008) Variations in practice patterns regarding constipation in children with urinary tract infections

Merenda et al. (2004) Bladder and bowel management for the child with spinal cord dysfunction

(10-21). Table-3 summarizes these studies, as well as, the LoE and GR, number of patients included in each study and their mean age. The important findings will be discussed in detail.

Loening-Baucke (10) published a cohort study evaluating the frequency of urinary incontinence and urinary tract infection in constipated children and the effect of successful treatment of constipation on urologic symptoms: 234 chronic constipated and encopretic children were evaluated before and at least 12 months after the treatment for constipation (mean follow-up $=15$ months), which was successful in $52 \%$ of the children. In this group, relief of constipation resulted in disappearance of daytime urinary incontinence in $89 \%$ and night-time urinary incontinence in $63 \%$ of patients, and disappearance of recurrent urinary tract infections in all patients who had no anatomic abnormality of the urinary tract. This study showed that with treatment of the constipation, most children became clean and dry and recurrence of urinary tract infections was prevented (LoE 1B / GR B).

McGrath et al. (11) performed a prospective cross-sectional study of children with enuresis at presentation to a continence service. Data relating to the child's bowel habits, pattern of enuresis and other history items were obtained from parental questionnaires and paediatrician's assessments. Of the 277 participants aged 4.8-17.5 years (median 8.6 years), $100(36.1 \%)$ were identified as constipated by the clinician, compared with only 39 (14.1\%) from parental reporting (Kappa $=0.155 ; \mathrm{P}=0.003$ ). Constipation was high among children with enuresis, but was often not recognized by parents (LoE 2 / GR B).

Kajiwara et al. (15) retrospectively studied the differences between monosymptomatic and nonmonosymptomatic enuresis on the basis of LUTS and constipation. Eighty-eight patients $(9.8 \pm 3.1$ years old $)$ were enrolled, 67 with monosymptomatic and 21 with non-monosymptomatic enuresis. Besides a history of urinary tract infections, mechanical obstructions and vesicoureteral reflux, constipation was also strongly associated with non-monosymptomatic enuresis compared to monosymptomatic enuresis (LoE 2 / GR C).

Bael et al. (12) studied the efficacy of treating urinary incontinence (UI) in children with concomitant functional fecal incontinence (FFI) or FC. After treatment of UI, FFI dropped from $32 \%$ to $21 \%(\mathrm{P}=0.035)$; for FC, the number of evaluated children was too small. Although the studied population was rather small, the outcome supports a mutual relationship between LUTS and bowel dysfunction (LoE 2 / GR B).

Koff et al. (13) performed a prospective cohort study to evaluate the prevalence of DES in children with vesicoureteral reflux and to determine whether functional bladder and/or bowel disorders influence the natural history or treatment of children with primary vesicoureteral reflux. One hundred and forty-three children with primary vesicoureteral reflux, that stopped spontaneously or was surgically corrected, were included. Unsuccessful surgical outcomes involving persistent, recurrent and con- 
Table 3 - Literature data on constipation and LUTS in children.

\begin{tabular}{ccccc}
\hline Refs. & $\begin{array}{c}\text { Level of } \\
\text { Evidence } \\
\text { (ICUD) }\end{array}$
\end{tabular} GR No. of Patients Mean Age Context

Loening-Baucke V.

(1997)

McGrath et al.

(2008)

Bael et al.

(2007)

Koff SA et al.

(1998)

Loening-Baucke V.

(2007)

Kajiwara M et al.

(2008)
1

B

234

9

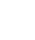

2

B

277

$(8.6$

6-12

202

$2 \quad$ B

(2)

(1)

Prospective cohort of paediatric patients to evaluate the frequency of urinary incontinence and urinary tract infections before and after treatment of constipation. Mean follow-up $=15$ months.

Prospective cross-sectional study to identify the prevalence of constipation in children with enuresis $(100 \%$ response rate)

Prospective multicentre study to evaluate the prevalence of symptoms of disordered defecation before and after treatment for UI in children ( $89 \%$ after 6 month-follow-up). However, very limited population (few patients with constipation; $n=14)$. No sample size estimation reported.

Not Prospective cohort study evaluating the reported prevalence of dysfunctional elimination syndrome in children with vesicoureteral reflux. Follow-up not reported.

4-17 Retrospective study to evaluate the prevalence rates for constipation and urinary incontinence in children

Retrospective study evaluating the prevalence of overactive bladder and constipation in children with primary enuresis 
Constipation and LUTS

Table 3 - Literature data on constipation and LUTS in children. - continued

\begin{tabular}{|c|c|c|c|c|c|}
\hline Refs. & $\begin{array}{l}\text { Level of } \\
\text { Evidence } \\
\text { (ICUD) }\end{array}$ & GR & No. of Patients & Mean Age & Context \\
\hline $\begin{array}{l}\text { De Paepe et al. } \\
(2000)\end{array}$ & 2 & $\mathrm{C}$ & 20 & 4.45 & $\begin{array}{c}\text { Pelvic-floor therapy and toilet training } \\
\text { in young children with dysfunctional } \\
\text { voiding. No control group. Very small } \\
\text { population. }\end{array}$ \\
\hline $\begin{array}{l}\text { Robson et al. } \\
\text { (2005) }\end{array}$ & 3 & $\mathrm{C}$ & 170 & $\begin{array}{l}>3.5 \text { (mini- } \\
\text { mal age at } \\
\text { inclusion) }\end{array}$ & $\begin{array}{l}\text { Case-control study of patients with } \\
\text { primary and secondary enuresis }\end{array}$ \\
\hline $\begin{array}{l}\text { Kasirga E et al. } \\
(2006)\end{array}$ & 3 & $\mathrm{C}$ & 69 & $\begin{array}{l}63.5 \\
\text { months } \\
\text { (case) and } \\
82 \text { months } \\
\text { (control) }\end{array}$ & $\begin{array}{l}\text { Case-control study to evaluate LUTS in } \\
\text { children with functional constipation }\end{array}$ \\
\hline $\begin{array}{l}\text { Erickson BA et al. } \\
(2003)\end{array}$ & 3 & $\mathrm{C}$ & 46 & 7.7 & $\begin{array}{l}\text { Retrospective study evaluating the use } \\
\text { of polyethylene glycol } 3350 \text { for consti- } \\
\text { pation in children with dysfunctional } \\
\text { elimination }\end{array}$ \\
\hline $\begin{array}{l}\text { Lucanto et al. } \\
\text { (2000) }\end{array}$ & 3 & $\mathrm{C}$ & 11 & 8.1 & $\begin{array}{l}\text { Case-series of paediatric patients with } \\
\text { chronic constipation and LUTS to } \\
\text { evaluate urodynamic characteristics and } \\
\text { bowel motility. }\end{array}$ \\
\hline $\begin{array}{l}\text { Chrzan R et al. } \\
(2008)\end{array}$ & 4 & $\mathrm{C}$ & 50 & 9.6 & $\begin{array}{l}\text { Retrospective study evaluating the use } \\
\text { of colonic enemas for persistent con- } \\
\text { stipation in children with dysfunctional } \\
\text { voiding. Very limited population. Only } \\
\text { descriptive results. }\end{array}$ \\
\hline $\begin{array}{l}\text { Chase et al. } \\
(2004)\end{array}$ & 4 & $\mathrm{D}$ & - & - & $\begin{array}{l}\text { Consensus on children with bowel dys- } \\
\text { function and LUTS. No Delphi consen- } \\
\text { sus statement reported }\end{array}$ \\
\hline
\end{tabular}

LUTS = Lower urinary tract syndrome; ICUD = International Consultation on Urological Disease; GR = grades of recommendation. 
tralateral reflux occurred only in children with DES. The authors concluded that dysfunctional elimination syndromes are common and are often unrecognized in children with primary reflux. These syndromes are associated with delayed reflux resolution and an increased rate of breakthrough urinary tract infection, which leads more frequently to reimplantation surgery (LoE 2 / GR B).

Loening-Baucke (14) evaluated the prevalence rates for constipation, as well as of faecal and urinary incontinence in children attending primary care clinics in the United States. 482 children (7-17 years of age) were included in the study. The prevalence rate for constipation was $22.6 \%$ and was similar in boys and girls. The prevalence rate for faecal incontinence ( $>$ or $=1 /$ week) was $4.4 \%$. Faecal incontinence was associated with constipation in $95 \%$ of the patients. The prevalence rate for urinary incontinence was $10.5 \%$; $3.3 \%$ for daytime only, $1.8 \%$ for day- and night-time and $5.4 \%$ for night-time urinary incontinence. Faecal and urinary incontinence were significantly more commonly observed in children with constipation than in children without constipation. Children with constipation had higher prevalence rates not only for faecal but also for urinary incontinence than children without constipation (LoE 2 / GR C).

De Paepe et al. (16) analysed the results after treating young children with LUTS and constipation, using a noninvasive training programme. Therapy consisted of keeping a voiding and drinking chart, instructions on proper toilet posture, daily rules for application at home, and if possible relaxation biofeedback of the pelvic-floor muscles. Twenty children were treated and 13 had a good result (became dry during the day and night, and encopresis resolved). This study shows that pelvic-floor muscle- and toilet training can improve both LUTS and constipation, but the studied population was very small and there was no control group (LoE 2 / GR C).

\section{CONSTIPATION AND LUTS IN MIDDLE- AGED WOMEN}

Constipation may affect 12 to $32 \%$ of middleaged women $(6,7)$. Women with constipation are more likely than men to seek medical attention or use medication for this condition. There are 5 studies examining the prevalence of constipation and its association with LUTS and/or POP in middle-age women $(6,7,22-24)$. These studies are summarized in Table-4.

Varma et al. (6) analysed data from a randomly selected cohort of 2,109 women, 40-69 years old, to describe the prevalence of obstructive defecation and identify associated risk factors. Obstructive defecation that occurred at least weekly was reported by $12.3 \%$ of women. Significant independent risk factors included vaginal or laparoscopic hysterectomy [odds ratio $(\mathrm{OR})=2.01 ; 95 \%$ confidence interval $(\mathrm{CI})=1.15-3.54]$, using three or more medications [1.81 (1.36-2.42)], symptomatic pelvic organ prolapse [2.34 (1.47-3.71)], urinary incontinence surgery [2.52 (1.29-4.90)], and other pelvic surgery [1.35 (1.03-1.78)]. Women who had undergone laparoscopic/vaginal hysterectomies or surgery for pelvic organ prolapse or for urinary incontinence had a nearly two times higher risk for obstructive defecation (LoE 2 / GR B).

Ewings et al. (22) performed a cohort study assessing risk factors for developing urinary incontinence following childbirth. A total of 723 women were recruited from the study. At 6 months post-partum, $45 \%$ of women reported some incontinence problems. Chronic constipation was the second strongest predictor for post-partum incontinence $(\mathrm{OR}=1.86 ; 95 \% \mathrm{CI}$ $=1.03-3.34$ ), along with a pre-existing incontinence problem [4.49 (3.09-6.53)] and episiotomy in at least one delivery [1.96 (1.25-3.07)] (LoE 2 / GR C).

Soligo et al. (7) analysed the prevalence and patterns of constipation in women with urinary symptoms and/or genital prolapse. Seven hundred and eighty-six consecutive urogynaecological patients participated in a questionnaire and structured clinical assessment. Thirty-two percent of women were constipated. A genital prolapse of grade 2 or more occurred in $44 \%$ of women. A posterior colpocele was more frequent in constipated women (35\% vs. $19 \%$; $\mathrm{p}<0.0001$ ), resulting in a risk factor for constipation $(\mathrm{OR}=2.31 ; 95 \% \mathrm{CI}=1.63-3.27)$. By contrast, higher degrees of anterior colpocele appeared to protect against constipation $[0.80(0.66-0.96)]$. Constipation correlated exclusively with posterior aspects of the pelvic floor support (LoE 2 / GR C). 
Constipation and LUTS

Table 4 - Literature data on constipation and LUTS in middle-aged women.

\begin{tabular}{|c|c|c|c|c|c|}
\hline Reference & $\begin{array}{l}\text { Level of } \\
\text { Evidence } \\
\text { (ICUD) }\end{array}$ & GR & $\begin{array}{l}\text { Number of } \\
\text { Patients }\end{array}$ & $\begin{array}{l}\text { Mean Age } \\
\text { (years) }\end{array}$ & Context \\
\hline $\begin{array}{l}\text { Varma MG et al. } \\
(2008)\end{array}$ & 2 & B & 2109 & 56 & $\begin{array}{l}\text { Population-based study to describe the } \\
\text { prevalence of obstructive defecation and } \\
\text { identify associated risk factors in middle- } \\
\text { aged women }\end{array}$ \\
\hline $\begin{array}{l}\text { Ewings et al. } \\
(2005)\end{array}$ & 2 & $\mathrm{C}$ & 723 & $\begin{array}{l}\text { Not reported } \\
(>16 \text { years } \\
\text { at inclusion) }\end{array}$ & $\begin{array}{l}\text { Prospective cohort study assessing risk } \\
\text { factors for IU following childbirth. Fol- } \\
\text { low-up }=76.9 \% \text { after } 6 \text { months. }\end{array}$ \\
\hline $\begin{array}{l}\text { Soligo M et al. } \\
\text { (2006) }\end{array}$ & 2 & $\mathrm{C}$ & 786 & 60 & $\begin{array}{l}\text { Retrospective study to evaluate the } \\
\text { prevalence and patterns of constipation } \\
\text { in women with LUTS or prolapse. No } \\
\text { detailed report of the urodynamic charac- } \\
\text { teristics of the patients. }\end{array}$ \\
\hline $\begin{array}{l}\text { Ng et al. } \\
(2002)\end{array}$ & 3 & $\mathrm{C}$ & 320 & 45.1 & $\begin{array}{l}\text { Cross-sectional study evaluating the } \\
\text { prevalence of anorectal dysfunction } \\
\text { among women with LUTS. }\end{array}$ \\
\hline $\begin{array}{l}\text { Spence-Jones et al. } \\
\text { (1994) }\end{array}$ & 3 & $\mathrm{C}$ & 73 & 52 & $\begin{array}{l}\text { Case-control study to evaluate bowel } \\
\text { dysfunction among patients with uterov- } \\
\text { aginal prolapse or stress UI. }\end{array}$ \\
\hline
\end{tabular}

LUTS = Lower urinary tract syndrome; UI = urinary incontinence; ICUD = International Consultation on Urological Disease; $G R=$ grades of recommendation.

Spence-Jones et al. (24) performed a casecontrol study to investigate the aetiological importance of constipation in patients with uterovaginal prolapse and urinary stress incontinence. Twentythree women with uterovaginal prolapse (mean age 57 years), 23 women with urinary stress incontinence (mean age 52 years) and 27 control women (mean age 52 years) were included. All three groups were comparable in terms of parity, age and birth weight of children. However, constipation as a young adult prior to the development of urogynaecological symptoms was significantly more common in women with uterovaginal prolapse $(61 \%$ vs. $4 \% ; \mathrm{P}<0.001)$ and women with urinary stress incontinence $(30 \%$ vs. $4 \% ; \mathrm{P}<0.05)$, compared to controls. At the time of consultation, $95 \%$ of the women with uterovaginal prolapse were constipated, compared with only $11 \%$ of control women. Constipation, in addition to obstetric history, appears to be an important factor in the pathogenesis of uterovaginal prolapse and stress urinary incontinence (LoE 3 / GR C).

$\mathrm{Ng}$ et al. (23) evaluated the prevalence of anorectal dysfunction among women with LUTS. All 320 women who attended the urogynaecological outpatient clinic for urodynamic evaluation were requested to complete a structured questionnaire. Forty-nine (15.9\%) women reported having anal incontinence. Constipation was reported by $100(31.5 \%)$ of the women. A multiple logistic regression analysis revealed that the main risk factor associated with anal incontinence and constipation was the presence of uterovaginal prolapse $(\mathrm{OR}=5.02 ; 95 \% \mathrm{CI}=2.19-11.5$ 
Constipation and LUTS

Table 5 - Case reports on constipation and LUTS in the literature (neuropathic patients).

\begin{tabular}{|c|c|c|c|}
\hline Refs. & $\begin{array}{l}\text { N. of } \\
\text { Patients }\end{array}$ & $\begin{array}{l}\text { Mean Age } \\
\text { (years) }\end{array}$ & Context \\
\hline Pannek et al. (2009) & 2 & 62.5 & Acute deterioration of bladder dysfunction due to constipation \\
\hline $\begin{array}{l}\text { Karatzoglou et al. } \\
(2008)\end{array}$ & 1 & 25 & $\begin{array}{l}\text { Patient with peripheral nerve sheath tumour presenting with } \\
\text { constipation and urinary retention }\end{array}$ \\
\hline Gividen et al. (2002) & 1 & 14 & $\begin{array}{l}\text { Improvement of neuropathic bladder and urinary incontinence } \\
\text { after antegrade continence enema procedure }\end{array}$ \\
\hline Milne HJ (2006) & 1 & 16 & $\begin{array}{c}\text { Pelvic Ewing's sarcoma. Constipation and recurrent urinary } \\
\text { tract infections at presentation }\end{array}$ \\
\hline
\end{tabular}

LUTS $=$ Lower urinary tract syndrome; $U I=$ urinary incontinence.

for anal incontinence; $\mathrm{OR}=1.78 ; 95 \% \mathrm{CI}=1.03-3.09$

for constipation) (LoE 3 / GR C).

\section{CONSTIPATION AND LUTS IN THE ELDERLY}

There is only one prospective cohort study, to our knowledge, evaluating the effect of alleviating constipation on LUTS in the elderly (1). Charach et al. studied fifty-two patients, aged 65-89 (mean 72 \pm 13 ) years, with chronic constipation and LUTS, recruited from gastroenterology and urology clinics.(1) All patients were generally mobile, sensitive and continent. Before treatment of constipation was initiated, patients completed a questionnaire regarding their constipation pattern, LUTS, sexual function and mood. The follow-up was 4 months. Successful treatment of constipation increased the number of weekly defecations from $1.5 \pm 0.9$ to $4.7 \pm 1.2(\mathrm{P}<0.001)$; patients spent less time on the toilet $(25 \pm 2.1$ versus $63 \pm 1.9 \mathrm{~min} ; \mathrm{P}<0.0001)$; fewer patients reported urgency ( 16 vs. $34 ; \mathrm{P}<0.001$ ), frequency ( 25 vs. 47 ; $\mathrm{P}<0.001)$ and burning sensation during urination $(6$ vs. $17 ; \mathrm{P}<0.05)$. At the same time, there was also an improvement in the scoring of urgency, frequency and burning sensation (from a baseline of 52 to 126, 131 and 95, respectively; $\mathrm{P}<0.001$ ). Urinary stream disturbances improved in 32 of the 52 patients $(\mathrm{P}<$ $0.001)$. Residual urine volume decreased from $85 \pm$ 39.5 to $30 \pm 22.56 \mathrm{~mL}(\mathrm{P}<0.001)$. There was also a significant decrease in the number of patients with bacteriuria events ( 5 vs. 17 ; $\mathrm{P}<0.001$ ), and an improvement in sexual activity and $\operatorname{mood}(\mathrm{P}<0.05)$. Treatment of constipation significantly improved LUTS, as well as, patient's mood, sexual activity and quality of life (LoE 2, GR B).

\section{CONSTIPATION AND LUTS IN THE NEUROPATHIC PATIENTS}

Neuropathic lower urinary tract dysfunction and neuropathic colorectal dysfunction, as in patients with spinal cord lesions, share several similarities. The affected nerves causing the dysfunction are similar and the pattern of bowel and bladder dysfunction may change over the years (25). However, there are only 
case-reports and review studies (26-30) addressing constipation and LUTS in neuropathic patients. Table5 provides the case-report studies published so far.

Only recently, Pannek et al. (26) published an interesting article reporting two cases with mechanical compression of the urinary bladder by an over distended bowel. The first patient (63 year-old male), who had post-traumatic paraplegia sub Th 7 since 17 years, was performing intermittent catheterization and was referred because of recurrent urinary tract infections and urinary incontinence. He showed a distended abdomen and palpable masses in the left lower quadrant. Digital rectal examination revealed massive stool masses. Computed tomography showed dilatation of the colon, completely filled with stool, compressing the bladder and the left ureter, resulting in upper urinary tract dilatation. The second patient (62 year-old male), with post-traumatic quadriplegia sub C 7 since 42 years, had undergone sacral deafferentation and implantation of a Brindley anterior root stimulator. He presented with urinary retention since 3 days, due to malfunction of the Brindley device. Physical examination revealed a minimally distended abdomen, but with palpable masses in the left lower quadrant. On digital rectal examination, lumps of hard stool were detected. Video-urodynamics demonstrated compression of the urinary bladder against the symphysis, making voiding impossible despite sufficient detrusor contractions. The patients were properly treated with evacuation by colonic hydrotherapy. After successful treatment of constipation, upper urinary tract dilatation resolved in the first patient, and in the second patient, after re-establishing the function of the Brindley device, with electrically driven defecation, stool impaction disappeared and electromicturition was possible. This case report shows that massive stool impaction due to neuropathic bowel dysfunction can mechanically impede bladder emptying.

\section{COMMENTS}

Much attention has been focused on the evaluation of colon, rectum and anus in children with chronic constipation with or without encopresis, but little thought has been given to a possible association to urinary tract symptoms, such as day- and night- time urinary incontinence, urinary tract infection, and urinary retention in these children (10), despite the well-known fact that the lower urinary tract and the lower bowel tract are interrelated structures (31). Anatomically bladder and rectum lay in close communication and share muscular structures of the pelvic floor. Nevertheless, it has been suggested that the distension of the rectum by stool impaction in constipated children presses on the bladder wall causing bladder outflow obstruction, as well as inducing detrusor overactivity (32). Urodynamic studies have reported detrusor overactivity in patients with functional constipation. Additionally, both, bladder overactivity and bowel dysfunction may lead to overactivity of the pelvic floor musculature, resulting in a high muscle tone, which again causes dysfunctional elimination of urine and faeces (Figure-1) (16). A comprehensive medical history along with physical examination must be done for every child either with LUTS and/or with chronic constipation and encopresis, bearing in mind the neighbouring organ systems. It has been shown that it is not enough only asking the parents about the bowel habits of the child, as constipation is frequently not recognized and reported by parents (11). Moreover, it is important to pay attention during the physical examination to findings suggesting stool impaction, such as abdominal masses and/or abdominal distension. Complementary ultrasound may provide additional information on filling condition of colon and rectum.

When a child presents with enuresis, it is for various reasons important to differentiate between monosymptomatic and non-monosymptomatic enuresis: it has been shown by Kajiwara et al. that constipation is more often found in association with nonmonosymptomatic enuresis (15). Also in the setting of vesicoureteral reflux, it makes sense to search for constipation, because this condition can cause delayed reflux resolution and urinary tract infections. In this situation, successful treatment of constipation could avoid breakthrough urinary tract infections, which are often an indication for reimplantation surgery (13). In children with constipation and concomitant LUTS, adequate treatment of constipation also improves or abolishes LUTS. Loening-Baucke et al. performed a prospective study in this context: disappearance of day- and night-time urinary incontinence, only by 


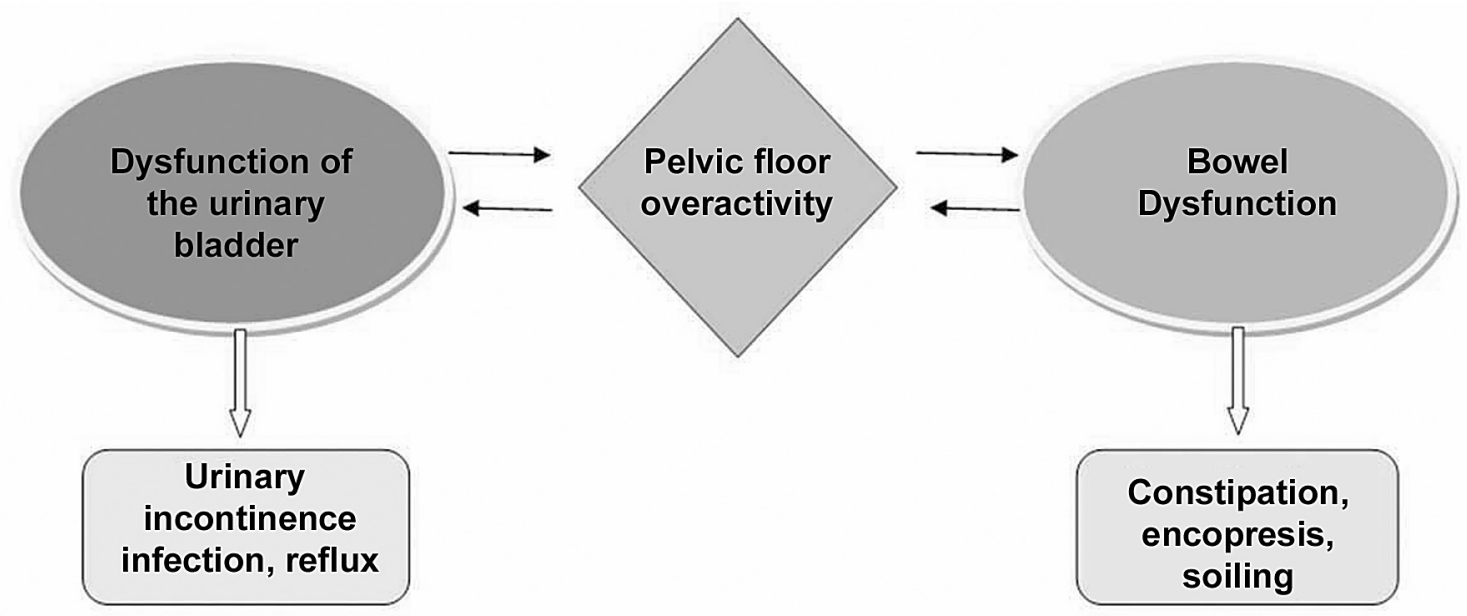

Figure 1 - Overactivity of pelvic floor muscles following bladder and bowel dysfunction*

* Modified according to De Paepe et al. (16)

treating constipation, occurred in $89 \%$ and $63 \%$ of patients, respectively. Additionally, urinary tract infections disappeared in all patients who had no anatomic abnormality of the urinary tract (10).

Constipation in women may significantly impact overall quality of life (33). Bowel habits must be investigated, especially in women with previous hysterectomy, pelvic organ prolapse and urinary incontinence surgery, as it was shown that these conditions are independent risk factors for constipation, probably due to an iatrogenic lesion of the innervation $(6,7,23)$. In contrast, constipation in young women is a risk factor for future uterovaginal prolapse and urinary stress incontinence (24). Constipation has frequently been described to increase the risk for pelvic organ prolapse (34). Pregnant women should have their bowel habits investigated, because there is good evidence that chronic constipation is a risk factor for postpartum urinary incontinence (22). When a pregnant woman presents with chronic constipation, one should treat this condition in time as an attempt to prevent postpartum urinary incontinence.

In community-based surveys, faecal incontinence (FI) is strongly associated with urinary incontinence and overactive bladder in both men and woman. Among nursing home patients, the association between urinary incontinence and FI is even stronger (35). It has also been shown that constipation and urinary symptoms are very common and disturbing in the elderly population (1). In the only prospective study addressing this problem in the elderly, Charach et al. (1) have shown that the treatment of constipation, at the same time, also improves or abolishes the urologic symptoms as urgency, frequency and burning sensation can be significantly improved after treatment of constipation. Besides, improvements in sexual activity and mood have been reported. Thus, it is important to take into consideration that treatment of chronic constipation in elderly patients, by appropriate use of stool softeners, adequate fluid intake, exercise and disimpaction if necessary, may also improve or even cure the urological symptoms.

Indeed, there are only a few case-reports addressing the relationship between neuropathic bowel dysfunction and neuropathic urinary tract dysfunction (26-30). It has been documented that overdistended bowel can mechanically impede bladder emptying and can cause upper urinary tract dilatation (26). This has to be considered, especially at long term follow-up, when upper and/or lower urinary tract unexpectedly deteriorates; in this situation it is mandatory to exclude stool impaction by abdominal palpation and digital rectal examination, as well as by a plain abdominal $\mathrm{X}$-ray, ultrasound and/or computed tomography. Colonic hydrotherapy is widely used for the treatment of this type of constipation. In these patients, with successful management of constipation, the urinary tract function can recover. 


\section{CONCLUSIONS}

Studies in children have linked constipation to urinary tract problems, including infections, enuresis, vesicoureteral reflux and upper renal tract dilatation. As a consequence of this interaction between bladder and bowel dysfunction, also overactivity of pelvic floor muscles is likely to occur. It is important in children with LUTS also to assess their bowel habits by taking a targeted history and proper clinical examination, as constipation may not be recognized and, thus, may not be reported by the parents. Studies in middle-aged women support a high prevalence of constipation among patients suffering from lower urinary tract dysfunction. There is some evidence for an association between constipation and urinary incontinence, as well as between constipation and POP and vice-versa. The only prospective study regarding the elderly population clearly shows that the medical relief of constipation significantly improves concomitant LUTS, which, in turn, improves the patient's mood, sexual activity and quality of life. Finally, the available data on neuropathic patients suggest that neuropathic bowel dysfunction with chronic constipation may mechanically cause urinary tract dysfunction. Chronic constipation and stool impaction may develop over many years, e.g. in spinal cord injured patients, and they are often subjectively unaware, of their condition which may be the reason for unexpected and otherwise unexplainable upper urinary tract deterioration and/or lower urinary tract dysfunction. In conclusion, despite the apparent relationship between constipation and LUTS, large scale, prospective, controlled studies are still needed, especially as regards the elderly and the neuropathic population.

\section{ACKNOWLEDGEMENTS}

We would like to thank Prof. Gisele Alsina Nader, from Federal University of Health Sciences of Porto Alegre - UFCSPA (Brazil), for her help in classifying the available studies on constipation and LUTS, according to the levels of evidence (LoE) and grades of recommendation (GR).

\section{CONFLICT OF INTEREST}

None declared.

\section{REFERENCES}

1. Charach G, Greenstein A, Rabinovich P, Groskopf I, Weintraub M: Alleviating constipation in the elderly improves lower urinary tract symptoms. Gerontology. 2001; 47: 72-6.

2. Buntzen S, Nordgren S, Delbro D, Hultén L: Anal and rectal motility responses to distension of the urinary bladder in man. Int J Colorectal Dis. 1995; 10: 148-51.

3. Drossman DA: The functional gastrointestinal disorders and the Rome II process. Gut. 1999; (45 Suppl 2): II1-5.

4. Bharucha AE, Wald A, Enck P, Rao S: Functional anorectal disorders. Gastroenterology. 2006; 130: 1510-8.

5. American College of Gastroenterology Chronic Constipation Task Force (2005) An evidence-based approach to the management of chronic constipation in North America. Am J Gastroenterol. 2005; 100(Suppl 1): S1-S4.

6. Varma MG, Hart SL, Brown JS, Creasman JM, Van Den Eeden SK, Thom DH: Obstructive defecation in middle-aged women. Dig Dis Sci. 2008; 53: 2702-9.

7. Soligo M, Salvatore S, Emmanuel AV, De Ponti E, Zoccatelli M, Cortese M, et al.: Patterns of constipation in urogynecology: clinical importance and pathophysiologic insights. Am J Obstet Gynecol. 2006; 195: 50-5.

8. Kistner M: Dysfunctional elimination behaviors and associated complications in school-age children. J Sch Nurs. 2009; 25: 108-16.

9. Chase JW, Homsy Y, Siggaard C, Sit F, Bower WF: Functional constipation in children. J Urol. 2004; 171: 2641-3.

10. Loening-Baucke V: Urinary incontinence and urinary tract infection and their resolution with treatment of chronic constipation of childhood. Pediatrics. 1997; 100: 228-32.

11. McGrath KH, Caldwell PH, Jones MP: The frequency of constipation in children with nocturnal enuresis: a comparison with parental reporting. J Paediatr Child Health. 2008; 44: 19-27.

12. Bael AM, Benninga MA, Lax H, Bachmann H, Janhsen E, De Jong TP, et al.: Functional urinary and fecal incontinence in neurologically normal children: symptoms of one 'functional elimination disorder'? BJU Int. 2007; 99: 407-12.

13. Koff SA, Wagner TT, Jayanthi VR: The relationship among dysfunctional elimination syndromes, primary 


\section{Constipation and LUTS}

vesicoureteral reflux and urinary tract infections in children. J Urol. 1998; 160: 1019-22.

14. Loening-Baucke V: Prevalence rates for constipation and faecal and urinary incontinence. Arch Dis Child. 2007; 92: 486-9.

15. Kajiwara M, Kato M, Mutaguchi K, Usui T: Overactive bladder in children should be strictly differentiated from monosymptomatic nocturnal enuresis. Urol Int. 2008; 80: 57-61.

16. De Paepe H, Renson C, Van Laecke E, Raes A, Vande Walle J, Hoebeke P: Pelvic-floor therapy and toilet training in young children with dysfunctional voiding and obstipation. BJU Int. 2000; 85: 889-93.

17. Robson WL, Leung AK, Van Howe R: Primary and secondary nocturnal enuresis: similarities in presentation. Pediatrics. 2005; 115: 956-9.

18. Kasirga E, Akil I, Yilmaz O, Polat M, Gözmen S, Egemen A: Evaluation of voiding dysfunctions in children with chronic functional constipation. Turk J Pediatr. 2006; 48: 340-3.

19. Erickson BA, Austin JC, Cooper CS, Boyt MA: Polyethylene glycol 3350 for constipation in children with dysfunctional elimination. J Urol. 2003; 170: 1518-20.

20. Lucanto C, Bauer SB, Hyman PE, Flores AF, Di Lorenzo $\mathrm{C}$ : Function of hollow viscera in children with constipation and voiding difficulties. Dig Dis Sci. 2000; 45: 1274-80.

21. Chrzan R, Klijn AJ, Vijverberg MA, Sikkel F, de Jong TP: Colonic washout enemas for persistent constipation in children with recurrent urinary tract infections based on dysfunctional voiding. Urology. 2008; 71: 607-10.

22. Ewings P, Spencer S, Marsh H, O’Sullivan M: Obstetric risk factors for urinary incontinence and preventative pelvic floor exercises: cohort study and nested randomized controlled trial. J Obstet Gynaecol. 2005; 25: 558-64. Erratum in: J Obstet Gynaecol. 2005; 25: 834-5.

23. Ng SC, Chen YC, Lin LY, Chen GD: Anorectal dysfunction in women with urinary incontinence or lower urinary tract symptoms. Int J Gynaecol Obstet. 2002; 77: 139-45.

24. Spence-Jones C, Kamm MA, Henry MM, Hudson CN: Bowel dysfunction: a pathogenic factor in uterovaginal prolapse and urinary stress incontinence. Br J Obstet Gynaecol. 1994; 101: 147-52.

25. Faaborg PM, Christensen P, Finnerup N, Laurberg S, Krogh K: The pattern of colorectal dysfunction changes with time since spinal cord injury. Spinal Cord. 2008; 46: 234-8.
26. Pannek J, Göcking K, Bersch U: 'Neurogenic' urinary tract dysfunction: don't overlook the bowel!. Spinal Cord. 2009; 47: 93-4.

27. Karatzoglou P, Karagiannidis A, Kountouras J, Christofiridis CV, Karavalaki M, Zavos C, et al.: Von Recklinghausen's disease associated with malignant peripheral nerve sheath thmor presenting with constipation and urinary retention: a case report and review of the literature. Anticancer Res. 2008; 28: 3107-13.

28. Gividen J, Van Savage JG: Improvement in neurogenic bladder after the antegrade continence enema procedure. Urology. 2002; 59: 137.

29. Milne HJ: An unusual cause of constipation presenting to the emergency department. Eur J Emerg Med. 2006; 13: 119-21.

30. Merenda L, Brown JP: Bladder and bowel management for the child with spinal cord dysfunction. J Spinal Cord Med. 2004; 27(Suppl 1): S16-23.

31. Wyndaele JJ, Kovindha A, Madersbacher H, et al.: Neurologic Urinary and Faecal Incontinence. In: Abrams P, Cardozo L, Khoury S, Wein A(ed.), Incontinence. Paris, Health Publication Ltd. 2009; Committee 10, pp. 797

32. O’Regan S, Yazbeck S, Hamberger B, Schick E: Constipation a commonly unrecognized cause of enuresis. Am J Dis Child. 1986; 140: 260-1.

33. Irvine EJ, Ferrazzi S, Pare P, Thompson WG, Rance L: Health-related quality of life in functional GI disorders: focus on constipation and resource utilization. Am J Gastroenterol. 2002; 97: 1986-93.

34. Koelbl H, Nitti V, Baessler K, et al.: Pathophysiology of Urinary Incontinence, Faecal Incontinence and Pelvic Organ Prolapse. In: Abrams P, Cardozo L, Khoury S, Wein A (ed.), Incontinence. Paris, Health Publication Ltd. 2009; Committee 4, pp. 283.

35. Norton C, Whitehead W, Bliss DZ, et al.: Conservative and Pharmacological Management of Faecal Incontinence in Adults. In: Abrams P, Cardozo L, Khoury S, Wein A (ed.), Incontinence. Paris, Health Publication Ltd. 2009; Committee 16, pp. 1333.

\section{Accepted after revision:}

June 7, 2010

\section{Correspondence address:}

Dr. Márcio Augusto Averbeck

Rua Soledade, 569 Bairro Três Figueiras

Porto Alegre, RS, 90470-340, Brazil

Fax: + $55513378-9996$

E-mail: marcioaverbeck@gmail.com 